\title{
Risks of enteral nutritional therapy: a clinical simulation
}

\author{
Riscos da terapia nutricional enteral: uma simulação clínica \\ Riesgos de la terapia nutricional enteral: una simulación clínica \\ Ana Paula Almeida Corrêa ${ }^{a, b}$ (iD \\ Carlise Rigon Dalla Norab \\ Gabriele Peres de Sousab \\ Valessa Jamile dos Santos ${ }^{c}$ \\ Graziela Lenz Viegas ${ }^{a}$ \\ José Luís Díaz Agead \\ Adriana Catarina de Souza Oliveirad ${ }^{d}$ \\ Mariur Gomes Beghetto ${ }^{b}$
}

GE Revista Gaúcha de Enfermagem

How to cite this article:

Corrêa APA, Dalla Nora CR, Santos VJ,

Viegas GL, Agea JLD, Oliveira ACS,

Beghetto MG. Risks of enteral nutritional

therapy: a clinical simulation. Rev Gaúcha

Enferm. 2020:41(esp):e20190159.

doi: https://doi.org/10.1590/1983-

1447.2020.20190159
Hospital de Clínicas de Porto Alegre (HCPA). Porto Alegre, Rio Grande do Sul, Brasil.

${ }^{b}$ Universidade Federal do Rio Grande do Sul (UFRGS), Escola de Enfermagem. Porto Alegre, Rio Grande do Sul, Brasil.

' Hospital Unimed Vale do Rio dos Sinos. Novo Hamburgo, Rio Grande do Sul, Brasil.

Universidade Católica Santo António de Múrcia. Faculdade de Enfermagem, Múrcia, Espanha.

\section{ABSTRACT}

Objective: Knowing the perceptions of nursing technicians about the risks to the patient in the use of enteral nutritional therapy, in a scenario of clinical simulation.

Method: A qualitative study, performed through a clinical simulation with nursing technicians from a university hospital in the South of Brazil, in August 2017. The simulation sessions were recorded in audio and later transcribed. Content analysis was used for data analysis. Results: Four thematic categories resulted from the analysis: Risks related to the tube; Risks related to diet; Risks related to contamination and Risks related to routine.

Conclusion: The clinical simulation allowed nursing technicians to identify risks in the practice of enteral nutritional therapy and ways to minimize them. Promoting spaces for continuing education in the service, using clinical simulation methodology, gives an opportunity for critical reflection, which can contribute to safer, effective and quality nursing care.

Keywords: Simulation training. Nutrition therapy. Enteral nutrition. Patient safety. Nursing care.

\section{RESUMO}

Objetivo: Conhecer a percepção dos técnicos de enfermagem sobre os riscos ao paciente em uso de terapia nutricional enteral, durante um cenário de simulação clínica.

Método: Estudo qualitativo, utilizou a simulação clínica com técnicos de enfermagem de um hospital universitário do Sul do Brasil, em agosto de 2017. As sessões foram gravadas em áudio e, posteriormente, transcritas. Para a análise dos dados utilizou-se a análise de conteúdo. Resultados: A análise resultou em quatro categorias: Riscos relacionados com a sonda; Riscos relacionados com a dieta; Riscos relacionados à contaminação e Riscos relacionados à rotina de cuidados.

Conclusão: A simulação clínica permitiu que os técnicos de enfermagem identificassem riscos na prática de administração de terapia nutricional enteral e meios de minimizá-los. Promover espaços para a educação permanente no serviço, utilizando metodologia de simulação clínica, oportuniza a reflexão crítica, o que pode contribuir para cuidados de enfermagem mais seguros, efetivos e de qualidade. Palavras-chave: Treinamento por simulação. Terapia nutricional. Nutrição enteral. Segurança do paciente. Cuidados de enfermagem.

\section{RESUMEN}

Objetivo: Conocer la percepción de los técnicos de enfermería sobre los riesgos para el paciente al emplear la terapia nutricional enteral, en un escenario de simulación clínica.

Método: Estudio cualitativo, realizado a través de una simulación clínica con técnicos de enfermería de un hospital universitario en el sur de Brasil, en agosto de 2017. Las sesiones de simulación se grabaron en audio y luego fueron transcriptas. Para el análisis de los datos, se utilizó el análisis de contenido.

Resultados: El resultado del análisis fueron cuatro categorías temáticas: Riesgos relacionados con la sonda; Riesgos relacionados con la dieta; Riesgos relacionados con la contaminación y Riesgos relacionados con la rutina.

Conclusión: La simulación clínica permitió que los técnicos de enfermería identificasen riesgos en la práctica de administración de terapia nutricional enteral y diversas formas de minimizarlos. Promover espacios para la educación permanente en el servicio por medio de la metodología de simulación clínica brinda oportunidades de reflexión crítica, lo que puede contribuir a cuidados de enfermería más seguros, efectivos y de calidad.

Palabras clave: Entrenamiento simulado. Terapia nutricional. Nutrición enteral. Seguridad del paciente. Atención de enfermería. 


\section{口INTRODUCTION}

Incidents related to Enteral Nutritional Therapy (ENT) may be directly linked to the insertion and maintenance of the Nasoenteric Tube (NET), as well as to the administration of therapy ${ }^{(1-2)}$. A cross-sectional study, which followed 150 NET insertions in patients admitted to an emergency department of a hospital in the South of Brazil, identified a breach of protocol for permission to NET use in 11 cases (no control X-ray was performed) and in 12 cases (X-ray examinations were not evaluated by the medical team, even though the tube was used), and in one of these cases there was a serious adverse event of bronchoaspiration (1). A cross-sectional study, also conducted in a hospital in the South of Brazil, followed 46 patients who used NET admitted to the Intensive Care Unit and to the Medical Clinic in order to verify the occurrence of adverse events related to ENT (2). $4.6 \%$ of cases of inadvertent NET exits and $2.1 \%$ of tube lumen obstruction were identified. It was also found that the administered diet volume was lower than the prescribed due to breaks in body hygiene, tests and procedures, nausea/vomiting and delays in dispensing the diet bottle (2)

Care measures related to the ENT administration involve a nursing team made up by the nurse, the technician and the nursing assistant, each professional with their particular duties according to regulation ${ }^{(3)}$. Therefore, patient safety on enteral diet depends on the process, surveillance and continuous evaluation of these professionals, demanding specific skills so that nutritional care occurs free of incidents and of adverse events that may be related ${ }^{(2)}$. Thus, a set of good practices in ENT directs the nursing staff, so that there is safety in all stages involved in the therapy, from indication of enteral diet, prescription, preparation, distribution, administration, to follow-up and monitoring of the patients ${ }^{(4)}$.

In the Brazilian context, it is up to the nursing technician working in ENT care: to participate in training on good practices in enteral nutrition therapy in the implementation of protocols aimed at maintaining safe care in the therapy administration phase, respecting hygiene care, correct identification and proper positioning of the tube and the patient during diet infusion; to promote general patient care according to the nursing prescription or the pre-established protocol; to communicate to the nurse any complications arising from nutritional therapy and to record the actions taken in the patient's record clearly, accurately and punctually ${ }^{(3)}$.

Knowing that nursing technician is an integral and indispensable part in the performance in ENT, the challenge is to insert him in the context of care so that within this work process they adopt practicable and safe practices, which include all the specificities of the administration and maintenance of the nasoenteric tube (NET) therapy ${ }^{(3)}$. In this sense, different education strategies for these professionals are used by health institutions with a focus on patient safety, one of them being clinical simulation ${ }^{(5)}$.

Clinical simulation is a teaching-learning strategy that promotes active participation by unifying theory with practice with opportunities for reproduction, feedback evaluation and reflection of the professionals, contributing to safety and to effective action ${ }^{(6)}$. To such end, simulators classified as low, moderate or high fidelity are used, according to their ability to accurately reproduce sounds or images. Low fidelity simulators are characterized by being static and are used for specific procedures, ideal for training skills $s^{(6)}$.

Considering that there are numerous complications that may be related to the use of ENT, there is an urgent need to develop educational practices that encourage nursing professionals to implement safe forms of therapy administration ${ }^{(7)}$. In this sense, low fidelity clinical simulation can be an ally for the training of good practice skills of the nursing team ${ }^{(8)}$, being considered adequate to review work processes ${ }^{(9)}$ and strongly associated with the prevention of adverse events ${ }^{(10)}$.

The present study aimed to evaluate if nursing team technicians were able to identify in a simulation scenario what the potential complications and/or adverse events were related to ENT that could be associated with their care practice. Thus, the research question is presented: "Are nursing technicians able to perceive nonconformities with the Good Practices of ENT management in a scenario of clinical simulation?" Thus, this study aims to know the perception of nursing technicians about the risks to patients using enteral nutrition therapy, during a scenario of clinical simulation.

\section{口 METHOD}

This is a descriptive research with qualitative approach $^{(11)}$, part of the intervention stage of the doctoral thesis entitled: "Effect of a clinical simulation intervention on nursing technician practices in patient care using a nasoenteral probe: a clinical trial", developed at the Federal University of Rio Grande do Sul (Universidade Federal do Rio Grande do Sul, UFRGS) Graduate Nursing Program. The present study qualitatively analyzed the recordings generated during the clinical simulation interventions of the clinical trial. 
The study was conducted in a high-complexity university hospital in the South of Brazil in August 2017. All the speeches of the nursing technicians who participated in the intervention stage (clinical simulation) of the matrix study were potentially eligible, considering an intentional sample and excluding those who were away from work during the data collection period. Thirty clinical simulation sessions were held, and each nursing technician participated in only one simulation session. Transcripts order of each session occurred in the same chronological order as the simulations. Data saturation occurred when information began to repeat in quantity and intensity and was adequate to understand multiple perceptions of nursing technicians about the risks to patients using ENT.

In order to perform the clinical simulation scenario, a low fidelity dummy was used, where nursing technicians should identify and correct errors in the care of patients using NET, which were inconsistent according to the institution's Standard Institutional Protocols (SIPs): difference between patient identification and diet label (name on diet bottle should match patient's bracelet), low headboard diet (should be at least $30^{\circ}$ ), tube attachment detached and dirty (fixation should be well fixed and clean), delayed diet administration (up to 3 hours), expired date of enteral diet equipment (up to 24 hours), dietary residue in syringe and plastic cup used to sanitize tube and equipment (syringes expiring every $6 \mathrm{~h}$ shift and plastic cups should be discarded each time), as well as not identifying these utensils (all should be properly labeled with patient label, name, medical record No., bed and validity). These SIPs follow the guidelines of Resolution 63/2000, especially regarding the inspection roadmap for ENT administration activities ${ }^{(4)}$. The scenarios lasted about 30 to 45 minutes during the participant's work shift.

Four nurses were the facilitators of the scenario, and were previously trained by the thesis nurse using the following documents, with the purpose of standardizing data collection: a) Training guide for good practice skills with the nasoenteral tube; b) Best practice simulation scenario with the nasoenteral tube; c) Checklist/evaluation of good practice skill training with nasoenteral tube. These nurses alternated in conducting the scenario, working in pairs, and playing the role of facilitators.

The facilitating nurse presented the scenario (Briefing), informing nursing technicians about the clinical case of the patient who used the NET and explained that the participants should identify the appropriate process of diet administration by NET. In the scene, the nursing technicians performed the roles of "acting" (TA) and of "Observer" (TO).

The Debriefing (moment aimed to reflect and review care routines for care with NET) was carried out in three phases: 1) acting technician's description/reaction: when the participant reports the scene and the perceptions during the simulated experience; 2 ) analysis/understanding: where the facilitator urges the acting technician and the observer to report the positive points and those to be improved during the service; and 3) synthesis/evaluation: when the facilitator resumes the good practices with the NET, recalls the complications and adverse events associated with the ENT and stimulates the discussion about how the experience helped them in the care practice.

All simulation sessions were recorded on a digital recorder, then fully transcribed and numbered according to the chronological performance order. It is noteworthy that participants'speeches may refer to the moment of the scenario itself or to the moment of debriefing, at which time there was discussion among all participants.

Data analysis followed the orientation of Bardin content analysis ${ }^{(12)}$, using the construction of categories obtained through exhaustive and thorough interviews reading. Operationally, this content analysis technique followed three major stages: pre-analysis; exploration of the material; treatment of results and interpretation ${ }^{(12)}$. In the pre-analysis data was organized, including the transcription of the recordings of each simulation and the reading of the field diaries; in this phase, the floating reading of each of the transcripts was performed. All the speeches were transcribed, but only those that dealt with risks and that were considered representative, were selected to elaborate indicators that support the interpretation. In the second stage, data was coded from the record units. In the last stage, the categorization was performed. It consisted in the classification of the elements according to their similarities and by differentiation, with subsequent regrouping, according to common characteristics.

The study was registered in the Clinical Trials (NCT 03497221) and was approved for its ethical and methodological aspects by the institution's

Research Ethics Committee (CAE: 63247916500005327). All participants signed the Free Informed Consent Form and the other ethical aspects of Resolution No. 466/2012 were observed. Participants' anonymity was guaranteed by identifying them with the letter " $A$ " of the simulation acting worker and with the letter " $\mathrm{O}$ " of the simulation observer, as well as by a number that corresponded to the simulation transcription order.

\section{QRESULTS AND DISCUSSION}

The study participants were 64 nursing technicians, of which $51.6 \%$ worked in the surgical unit and $48.4 \%$ in 
the clinical unit, distributed in the morning (28.1\%), afternoon (32.8\%) and evening shifts (39.1\%). Most (84.4\%) were women, with a median of 6 (IIQ: 4-15) years of work in the institution. More than half (59.4\%) had already done some training or institutional capacity building on care for patients using ENT, while $26.6 \%$ said they had not and $14.1 \%$ did not remember.

The data analysis process resulted in the organization of four thematic categories: Risks related to the tube; Risks related to diet; Risks related to contamination and Risks related to the care routine.

\section{Risks related to the tube}

This first category presents the participants' perception of the risks that are directly related to the patient care with the tube. The participants expressed risk perceptions related to dietary bronchoaspiration, to inadvertent traction of the tube, to tube obstruction and to skin injury caused by friction.

Thus, one of the main risks described by the participants is that of dietary bronchoaspiration. This risk may be related to the low position of the patient's headboard while receiving the ENT, as expressed in their speeches:

Headboard down! Patient could inhale from the low headboard. (TA 1).

What strikes me the most is to arrive and see the patient receiving a diet completely lying down. Then I will position him better, I will position him in bed while receiving the diet (TE 8).

Neglect. Especially when I arrived and saw the patient, something we see a lot, with the headboard down. You have to be careful with the diet, right? Headboard up (TA 10).

Raising the headboard due to the risk of aspiration is one of the most serious things (TO 12).

When I got there, I saw the headboard down... it can't happen. He may have aspiration pneumonia because of the $\operatorname{diet}($ TA 21).

I got to the room, and soon saw that the headboard was down. First thing I did, was to see that the diet was infusing. I closed the diet, positioned the headboard and told the nurse (TE 2).

This nursing technician's perception meets what is described in the literature. There is evidence to support the claim that maintaining the patient with a nasoenteric tube in the supine position increases the incidence of gastroesophageal reflux and the risk of aspiration, then, pneumonia ${ }^{(13)}$. The study ${ }^{(13)}$ also indicated concern about the height of the patient's headboard.

Still, a recurring theme in the participants' speeches was the risk of inadvertent traction of the tube.

Take care of the tube fixation, because sometimes they sweat a lot then it falls (TA 15).

Fixing of the tube... this tube is loose. Any movement the patient makes with the head, it can come out. Fixation is very important (TA 1).

In this case, the tube is not well placed, well fixed. In the past, we tested with the stetho. Now it is by measure. Then I would measure the tube, look if the fixation is well placed, because it can often come loose from the patient (TE 7). A patient who coughs a lot, the tube moves. Because of the cough, you have tubes that even come out because of the cough (TO 1).

Tube attachment is loose. I will change it (TA 3).

A study ${ }^{(2)}$ corroborates the results found by indicating that the inadvertent exit of the tube may be caused by the patient (psychomotor agitation, sedatives, mental confusion), or when the nursing team performs an inadequate translocation of the patient. Thus, the inadvertent exit of the NET is considered an indicator of quality of care provided by the nursing staff and, in the literature(2), the incidence found in a clinical medical unit was $4.6 \%$. The unwanted traction and exit of the tube may be associated with the fact that patients are conscious and agitated, often requiring mechanical containment, in addition to the lack of continuous surveillance by the nursing staff(2). Still, in the literature, authors ${ }^{(14)}$ detected the rupture of the balloon, the inadvertent removal of the tube by the patient, inadequate fixation, obstruction, and withdrawal in the procedure (bath) as reasons related to unplanned extubations.

Nursing technicians during the simulation also indicated the importance of following routines to avoid tube obstruction.

One simple thing, not washing the equipment or tube, can create a disturbance. Sometimes the patient goes on for a long time without receiving the diet because we ended up administering medication and the heavy medication blocked the tube and the nurse had to pass the tube again and the patient is waiting a while. Such a simple routine thing (TA 16).

Some medications block the tube. There is also an oily medication that sticks to the tube walls (TO 16). 
It is important to wash the tube to avoid obstruction (TO 20).

According to the literature ${ }^{(2)}$, tube obstruction is one of the most common mechanical complications in patients using ENT. It may occur due to lack of water irrigation before and after drug administration, diet precipitation, tube folds and elbows. A study ${ }^{(2)}$ also reports the incidence of tube obstruction in $0.021 / 100$ patients using ENT due to failure to effectively clean the ENT. Similarly, as presented in our study, tube obstruction may be related to drug administration due to high viscosity and insufficient ENT flow, incompatibility between diet and drug, drug adherence to the tube wall, characteristics or form of the medication ${ }^{(15)}$.

For nursing technicians, care to avoid skin injury is also essential in nursing routines.

It's dirty... To change the fixation, when we shower every day I look if the fixation is clean, if it is I do not change to avoid wounds, it prevents skin wounds (TO 5).

From what is said in the courses and what the boss speaks, because it causes skin damage (TO6).

Skin lesions may be related to improper tube placement and to the material used for fixation ${ }^{(2)}$. In this sense, periodic evaluation and daily change of tube fixation are fundamental nursing care measures for the prevention of these lesions ${ }^{(2)}$. Signs such as hyperemia, humidity, traction, friction, and discomfort should be observed daily in the care of these patients ${ }^{(7)}$.

As can be evidenced, all risks perceived by the participants generate major damage to the health of the patient using ENT. On the other hand, what is noticeable is the great concern of nursing technicians regarding the risk of bronchoaspiration and of inadvertent traction of the tube. It can be reflected that workload, worker deficit and care complexity in ENT may contribute to these events occurring more frequently in the service.

\section{Risks related to diet}

In this category, the identified risks are related to improper diet administration. Thus, the themes in this category refer to the risk of malnutrition and to the risk of dietary change among the patients.

Unintentionally, the nursing staff can contribute to the development of malnutrition on the patient. The reports have shown that it is critical to prioritize nutrition care. Diet therapy is a very important factor (TA 4).
[...] did not receive the diet, all the calories, dehydration, risk of death (TO 10).

Diet administration is important. Only when the patient is very nauseated, with vomiting or often they do not want. Patient when lucid: - Oh no, it's too much diet I don't want it again (TA 3).

[...] when the patient is satisfied, then we don't give the diet and it is recorded that the patient did not receive it (TA 3).

A study ${ }^{(16)}$ corroborates these results by indicating weaknesses in the nutrition offered to patients, related to the quantity and quality of therapy, which is a recurrent problem in several regions of Brazil. Thus, in-hospital malnutrition may be caused by inadequate diet ${ }^{(2)}$. Malnutrition in hospitalized patients should be avoided as it is associated with a higher risk of comorbidities and mortality ${ }^{(17)}$, which may prolong the length of stay.

Diet switching among the patients may be related to the infusion of diets and hydration waters intended for one patient to another. In the participants' reports, the need to pay attention to the reading of identification labels and bracelets is evident, avoiding the exchange of therapies.

Checking his chart and diet too, it is very important (TA 1). It's changed; there is water from another patient (TO 3).

I noticed several bottles are not for the patient, with different names, I would use the one with the patient's name (TO 5).

In case this one is not the patient's, could not use, because it is not the correct patient (TA 6).

Patient identification is one of the things we do. Withdrawing the bottle that doesn't belong to the patient, must not be left on the table (TO 12).

In order to prevent feeding changes among patients, the Standard Operating Protocols (SOPs) and the ANVI$S A^{(4)}$ Best Practice guidelines on the ENT are developed to standardize the care of these patients, avoiding incidents. The nursing staff has a fundamental role in care with the administration of nutrition and they should check the following: medical record, bottle label, patient name, route of administration, volume and time ${ }^{(3)}$.

In this category, the number of reports about diet change among patients was higher, indicating that nursing technicians have problems related to the lack of effective communication with the patient, which could guarantee an adequate identification, as well as the lack of proper registration of labels by co-workers may reflect a break in the continuity and quality of care provided. 


\section{Risks related to contamination}

This thematic category addressed elements related to the risk of ENT contamination by the nursing staff. Among the themes identified are the hygiene of hands and of the devices used for the maintenance of the ENT, and the validity of inputs and diet.

The participants stressed the importance of hand hygiene as a way to prevent the spread of intra-hospital infections.

To avoid contamination to the patient, hand washing would also be a form of care (TA 6).

I wash my hands or use alcohol gel, I adjust the headboard, here... to administer the diet (TA 5).

I sanitize my hands and introduce myself to him (TA 20).

In a systematic review ${ }^{(18)}$, the mean adherence to hand hygiene was $34.1 \%$, with a mean rate of $56.9 \%$ after intervention strategies to improve hand hygiene. A study ${ }^{(19)}$ conducted in a hospital in the South of Brazil showed that only $27.2 \%$ of the professionals perform hand hygiene after contact with the environment close to the patient. There are five moments for hand hygiene: before touching the patient; before performing the clean/aseptic procedure; after a risk of exposure to body fluids; after touching the patient and after contact with surfaces close to the patient ${ }^{(19)}$. Therefore, hand hygiene is one of the main strategies for the prevention of health care-related infections ${ }^{(18)}$. Similarly, poor hygiene of utensils was evidenced as a possible source of bacteria proliferation ${ }^{(18)}$. Thus, by analyzing these results we can highlight the human and physical potential in causing risks to the health of the patients.

Still related to the risk of contamination, the participants referred to the need to be careful with the hygiene of the infusion pump used for the administration of the diet.

Pump hygiene is important. Usually the pumps are sanitized at night. But not that I will necessarily have to wait for the night shift to clear the bomb, right? If it is dirty, it's a matter of consistency (TA 1).

In our sector, thankfully, we don't even see a dirty bomb. I don't notice that it's dirty. Because we take it off, and already do the hygiene. When we take it off, it's dirty, we already have to do the hygiene (TO 10).

The use of the ENT infusion pump assists continuous and regular administration without oscillations in the infused volumes ${ }^{(2)}$. The infusion pump should preferably be exclusively used for administering the ENT, and cleaning and disinfection guidelines should be performed as recommended by the Hospital Infection Control Committee, with preventive and corrective maintenance to ensure proper functioning ${ }^{(4)}$. Therefore, it is critical that the nursing staff follow the diet infusion protocol $\left({ }^{(4)}\right.$, and that they maintain ongoing staff training and systematization of care to improve ENT management.

The respondents highlighted the importance of the attention to the validity of the supplies and the diet used in the ENT, which can pose risks to the patient through contamination.

No, this diet has already expired. This diet is expired. (TA 1).

The patient was receiving a diet that had expired since $23 \mathrm{~h}$

(TA 1).

I think the expired diet can cause diarrhea (TA 1).

I saw that the washing glass has nothing to do with the patient's name, I do not know how long it is here, I then discarded this water here, I take a new syringe, because the syringe is from the 27th (TA 4).

And the equipment, it is overdue (TA 6).

The equipment has expired since the 28th, today is the 31st (TO 9).

I think it's a lot of risks right? It may even may even make a bacteremia (TA 9).

The author ${ }^{(20)}$ corroborates our findings by indicating that contamination of enteral nutrition can be attributed to inadequate disinfection procedures for equipment, utensils and surfaces during preparation, for ingredients and other supplements used in the formulation, and because of improper storage and transportation conditions. According to the resolution of the National Health Surveillance Agen$c y^{(4)}$, all enteral nutrition must have the expiration date on the label indicating the conditions for its conservation. The enteral nutrition (EN) bottle in open or closed system is inviolable until the end of its administration. Similarly, EN infusion set should be fit for this purpose, and changed every 24 hours in accordance with the institution's Good Practices Standard Operational Protocols (SOPs) in ENT. A study ${ }^{(20)}$ indicates that manual contact is one of the most significant sources in the problem of enteral diet contamination in clinical settings. Thus, only by following the principles of asepsis, antisepsis and proper use of the equipment it is possible to ensure safety in the administration of the ENT.

There are several risks of ENT contamination by the nursing staff, but it is observed that the participants stop at those risks that refer to the validity time of the supplies and the diet used, to the detriment of the others. In order to control the risks of contamination in ENT, health education 
for all workers involved in the sector is essential. Education in the workplace supports workers in order to perform their duties with greater safety and quality, and is a requirement of all health care services.

\section{Risks related to the care routine}

In this category, the risks that are related to the care routine of patients in ENT are highlighted, either through the "automation of care" of the nursing technicians' team, as well as by people outside the nursing team.

Nursing technicians, with the practice acquired over time, risk "automating" the care provided, that is, tasks that technicians already do automatically and that can compromise patient safety.

Even we have been working here for so long, we do it on automatic. When we talk, it gets harder: stop and think a little (TA 1).

Truth is that we are like a machine, because you are in an automatic thing and some things eventually happen, we have no control (TA 4).

It's good, because it's such an automatic thing that you end up doing it. We do it on automatic, don't realize (TO 9).

In analyzing the causes of incidents, a study ${ }^{(21)}$ points out that they may be related to the human factor, that is, they are related to nursing professionals who handle the ENT. Some factors cited are time pressure, multiple activity or multiple shifts, fatigue, memory confidence for large amounts of information, lack of human resources, and training ${ }^{(21)}$.

In order to prevent care from occurring "automatically" Anvisa(4) recommends that the professionals develop, review and regularly update guidelines and procedures regarding the patients and the operational aspects of the ENT to avoid harm to the patients. Similarly, the educational aspect is another indicated strategy to help minimize the risks associated with the ENT ${ }^{(21)}$.

The participants also report that there are people outside the nursing staff (such as the service provided by the hospital pantry) that may compromise patient safety. That is, they are risks that are not directly related to the routine of the nursing staff, but to the actions of other people who also take care of this patient.

Sometimes you have to trust the kitchen, because there is no prescription. They (the nutrition attendants) don't always drop (the diet bottle) at the patient's bedside. They leave it at the (nursing) post. We take (the diet) (TA 2).
The patient's name with the diet also has to be taken care of, because sometimes the kitchen can go on and deliver the wrong diet, and something goes wrong for the patient (TA6).

But why? Whose commitment is it? This commitment is from the kitchen (TA 21).

Because I already took the diet they gave (the kitchen) from one patient to another (TA 6).

The hospital must have a structured nutrition and dietary service, organized and integrated with other areas of care, with the function of providing food and nutritional assistance with quality and safety from a hygienic and sanitary point of view, providing guidance to the patients, monitoring effects and diet acceptance ${ }^{(4)}$. Thus, the maids should be properly trained for this type of service, since most patients using ENT are at risk, and there is a need to carefully treat the distribution of diets so that the correct diet helps in the evolution of the nutritional status and the consequent clinical improvement ${ }^{(4)}$.

In this sense, considering that health services are provided in complex environments, such as in hospitals, several factors may contribute to the occurrence of care-related incidents. Regarding the risks related to care routines, it is observed that the participants report that other members of the health team may also interfere with care, so it is necessary to identify and treat the risks to which patients in use of ENT are then submitted in view of all the workers involved.

The National Patient Safety Program (22), created in 2013, aims to promote and support the implementation of initiatives aimed at patient safety in different areas of care, organization and management of health services, through the implementation of risk management and of Patient Safety Centers in health facilities. Thus, risk reduction is closely related to the establishment of a patient safety culture, which presupposes learning from the failures and preventing new incidents related to health care. Therefore, it is essential to disseminate knowledge among other team professionals, in order to prevent the occurrence of incidents in health services.

As regards the simulation, it is noteworthy that most of the speeches that reflected the perception of the nursing team about the risks of the ENT came from the acting technician. Thus, in this study the debriefing was evidenced as a moment to deepen the reflection on the risks. A study ${ }^{(23)}$ asserts that the debriefing is the key moment of clinical simulation, when the participant reflects on their conduct and understands what is missing to achieve the desired competence. On the other hand, it is noteworthy that during the development of the simulation scenario (in scene) the 
participants did not "realize" the nonconformities present in the simulation (data from the clinical trial being published).

The simulation tried to portray the most reliable scenario possible, being performed in a room adjacent to the assistance area of the nursing technicians; this care contributed to the reliability of the scenario, increasing the immersion of participants in the activity. The room was equipped as described in the method when the scenario was described. A study ${ }^{(5)}$ reinforces that the fidelity of the scenario is of utmost importance, especially when performed with health professionals. The subject of safety in ENT is not easy to approach in educational actions; in this sense, it is made possible through the simulation of everyday actions, in a risk-free environment, which allows the discussion of the risks of the process of ENT care.

In this sense, it can be reflected that the professionals are not used to working with simulation in their services, although this methodology has already shown that they develop skills such as decision making, communication and teamwork ${ }^{(5)}$. Thus, the need for health institutions to propose continuing education actions based on real cases, through simulation, is essential for the adoption of safe practices in patient care. It can be suggested that the integration with others involved in the care of patients using ENT, since this study highlighted the professionals of the pantry, also deserve to be integrated in the simulations with a view to a broader approach to the educational practice.

The need to invest in the construction of scenarios based on real facts deserves a special mention, in the realization of the detailed design to be as realistic as possible, in addition to the need to invest in the qualification of the facilitating professionals, the detailed planning of the scenarios and the organization at the time of their application, so that they can perform a problematizing debriefing.

The fact that this study exclusively included nursing technicians from a single hospital may make it difficult to generalize the findings to other contexts. In addition, the fact that the original study (clinical trial) was designed for another purpose may also constitute a limitation. Still, the results show that the nursing technicians perceive many of the risk factors related to enteral tube diet administration. In addition, our findings give rise to new research studies to better understand the ways in which nursing staff acquire knowledge, skills and attitudes during care for patients with ENT.

\section{- CONCLUSION}

During the simulation, the nursing technicians noticed that there are risks related to the tube, which involve dietary bronchoaspiration, inadvertent tube exit, tube obstruction and skin injury. Risks related to ENT contamination were also noted, which refer to poor hygiene of hands and utensils and to the validity of diet and inputs. Diet-related risks included malnutrition and diet switching among patients. Similarly, risks related to the care routine in ENT refer to the automation of care and people outside the nursing staff.

The data herein presented can serve as subsidies to the health services, in order to compose an effective and quality simulation for the nursing team and can also be expanded to the multi-professional team of ENT such as the presence of doctors, nutritionists and pharmacists. Thus, everyone will have access to periodic permanent health education within the hospital setting in which they work, with a view to minimizing ENT-related incidents.

Similarly, the findings of the present study allow us to support the use of clinical simulation as a methodology that makes it possible, especially at the time of the debriefing, to highlight the nonconformities present in the ENT routine and to bring these data up for analysis and discussion in a reflective and joint manner. This study showed that simulation is a very useful methodology for reviewing the good practices in ENT with regard to skill training.

\section{REFERENCES}

1. Anziliero F, Beghetto MG. Incidents and adverse events in enteral feeding tube users: warnings based on a cohort study. Nutr Hosp. 2017;35(2):259-64. doi: https://doi.org/10.20960/nh. 1440

2. Cervo AS, MagnagoTSBS, Carollo JB, Chagas BP, Oliveira AS, Urbanetto JS. Adverse events related to the use of enteral nutritional therapy. Rev Gaúcha Enferm. 2014;35(2):53-9. doi: https://doi.org/10.1590/1983-1447.2014.02.42396

3. Conselho Federal de Enfermagem (BR). Resolução no 453, de 16 de janeiro de 2014. Aprova a Norma Técnica que dispõe sobre a Atuação da Equipe de Enfermagem em Terapia Nutricional. Diário Oficial da União. 2014 jan 28;151 (19 Seção 1):78-9.

4. Agência Nacional de Vigilância Sanitária (BR). Resolução no. 63, de 6 de julho de 2000. Aprova o Regulamento Técnico para a Terapia de Nutrição Enteral. Diário Oficial [da] República Federativa do Brasil. 2000 jul 7;138(130-E Seção 1):8999.

5. Cogo ALP, Lopes EFS, Perdomini FRI, Flores GE, Santos MRR. Building and developing realistic simulation scenarios on safe drug administration. Rev Gaúcha Enferm. 2019;40(spe):e20180175. doi: https://doi.org/10.1590/19831447.2019.20180175

6. Quilici AP, Abrão K, Timerman S, Gutierrez F. Simulação clínica do conceito à aplicabilidade. Rio de Janeiro: Atheneu; 2012.

7. Blumenstein I, Shastri YM, Stein J. Gastroenteric tube feeding: techniques, problems and solutions. World J Gastroenterol. 2014;20(26):8505-24. doi: https://doi.org/10.3748/wjg.v20.i26.8505

8. Meska MHG, Mazzo A, Jorge BM, Souza-Junior VD, Negri EC, Chayamiti EMPC. Urinary retention: implications of low-fidelity simulation training on the selfconfidence of nurses. Rev Esc Enferm USP. 2016;50(5):833-9. doi: https://doi. org/10.1590/s0080-623420160000600017 
9. Cheng A, Grant VAM. Using simulation to improve patient safety: dawn of a new era. JAMA Pediatr. 2015;169(5):419-20. doi: https://doi.org/10.1001/ jamapediatrics.2014.3817

10. Groves P, Bunch J, Cram E, Perkhounkova Y. Development and feasibility testing of a patient safety research simulation. Clin Simul Nurs. 2018;15:27-33. doi: https://doi.org/10.1016/j.ecns.2017.09.007

11. Minayo M. 0 desafio do conhecimento científico: pesquisa qualitativa em saúde. 14. ed. São Paulo: Hucitec; 2014.

12. Bardin L. Análise de conteúdo. São Paulo: Edições 70, 2011; 2011.

13. Viana J, Balinha J, Afonso C. Monitorização do volume de resíduo gástrico no doente crítico. Acta Port Nutr. 2017 [cited 2019 Apr 10];(10):38-42. Available from: http://www.scielo.mec.pt/pdf/apn/n10/n10a06.pdf

14. Naves LK, Tronchin DMR. Home enteral nutrition: profile of users and caregivers and the incidents related to feeding tubes. Rev Gaúcha Enferm. 2018;39:e20170175. doi: https://https:/.doi.org/10.1590/1983-1447.2018.2017-0175

15. Ferreira Neto CJB, Plodek CK, Soares FK, Andrade RA, Teleginski F, Rocha MD. Pharmaceutical interventions in medications prescribed for administration via enteral tubes in a teaching hospital. Rev Latino-Am Enferm. 2016;24:e2696. doi: https://doi.org/10.1590/1518-8345.0619.2696

16. Gonçalves EC, Morimoto IMI, Ribeiro CSG, Cunha TR, Corradi-Perini C. Bioethics and the human right to adequate feeding during enteral nutritional therapy. Rev Bioética. 2018;26(2):260-70. doi: https://doi.org/10.1590/198380422018262247

17. Vargas PM. Avaliação do estado nutricional de pacientes em uso de terapia nutricional enteral. Rev Bras Obesidade Nutr Emagrec. 2018 [cited 2019 Mar 20];12(75):830-40. Available from: http://www.rbone.com.br/index.php/ rbone/article/view/801

18. Kingston L, O'Connell NH, Dunne CP. Hand hygiene-related clinical trials reported since 2010: a systematic review. J Hosp Infect. 2016;92(4):309-20. doi: https://doi.org/10.1016/j.jhin.2015.11.012
19. Souza LM, Ramos MF, Becker ESS, Meirelles LCS, Monteiro SAO. Adherence to the five moments for hand hygiene among intensive care professionals. Rev Gaúcha Enferm. 2015;36(4):21-8. doi: https://doi.org/10.1590/19831447.2015.04.49090

20. Santos S. Descrição da qualidade microbiológica das fórmulas enterais e da água de um hospital particular de Fortaleza - Ceará. Rev Assoc Bras Nutr. 2016 [cited 2019 Mar 10];7(2):38-48. Available from: https://www.rasbran.com.br/ rasbran/article/view/104/140

21. Matsuba C, Macedo LC, Weber B, Ciosak S. Gerenciamento de riscos em terapia nutricional: qual a percepção da equipe multiprofissional? [resumo]. Braspen J. 2017 [cited 2019 Jan 10];32(supl. 2):50. Resumos do XXII Congresso Brasileiro de Nutrição Parenteral e Enteral. Available from: https://pt.calameo.com/ read/0050107686530ee511ec0

22. Ministério da Saúde (BR). Portaria no 529, de 10 de abril de 2013. Institui 0 Programa Nacional de Segurança do Paciente (PNSP). Diário Oficial da União. 2013 abr 02;150(62 Seção 1):43-4.

23. Oliveira SN, Massaroli A, Martini JG, Rodrigues J. From theory to practice, operating the clinical simulation in nursing teaching. Rev Bras Enferm. 2018;71(4):1896-903. doi: https://doi.org/10.1590/0034-7167-2017-0180

FINANCING: Coordination for the Improvement of Higher Level Staff (Coordenação de Aperfeiçoamento de Pessoal de Nivel Superior, CAPES), scholarship of the National Post-Doctorate Program (Programa Nacional de Pós-Doutorado, PNPD) developed in the Nursing Post-Graduate Program of the Federal University of Rio Grande do Sul. Overseas Doctorate Program (Programa de Doutorado Sanduíche no Exterior, PDSE). Process No. 88881.135577/201601. Fund for the Incentive of Research of the Hospital de Clínicas de Porto Alegre (HCPA) Registration No. 32368.
- Corresponding author:

Carlise Rigon Dalla Nora

E-mail: carliserdn@gmail.com
Received: 05.06.2019

Approved: 08.15.2019 